\title{
LAS POETAS EN LA REVISTA LITERARIA MEXICANA RUECA (1941-1952)
}

\author{
POETS IN THE MEXICAN LITERARY REVIEW RUECA \\ (1941-1952)
}

\author{
Lilia Solórzano Esqueda \\ Universidad de Guanajuato, México. \\ liliasolorzano@hotmail.com
}

\section{Resumen:}

Este ensayo intenta integrar un mapa, una ruta de viaje por los contenidos de la revista literaria mexicana Rueca publicada entre los años 1941-1952. Uno de los primeros esfuerzos nacionales serios de mujeres jóvenes, estudiantes y escritoras, auspiciado por la Facultad de Filosofía y Letras de la Universidad Nacional Autónoma de México. La publicación hizo frente al inexistente panorama de proyectos editoriales dirigidos por mujeres que no consistieran únicamente en textos sentimentales o dirigidos a mejorar asuntos del hogar.

Palabras clave: Rueca, revistas literarias mexicanas, Carmen Toscano, María Ramona Rey.

\section{Abstract:}

This essay attempts to integrate a map, a route of travel for the content of the Mexican literary magazine Rueca published between the years 1941-52. One of the first serious national endeavor of the young women, students and writers, sponsored by the Facultad de Filosofía y Letras, Universidad Nacional Autónoma de México. The publication faced the non-existent scene of publishing projects led by women who do not only consist of emotional discourses or directed to improve the domestic affairs.

Keywords: Rueca, Mexican literary magazines, Carmen Toscano, María Ramona Rey.

Todo "empezó en alguna clase de Filosofía y Letras. Emma Saro, discreta, de carácter decidido [...] dueña de una imprenta [...propuso] 'Hagamos una Sociedad de Literatura [...], y podemos publicar una revista. Yo regalo el primer número" " (Toscano 94). Así lo cuenta Carmen Toscano, una de sus fundadoras. Y del otoño de 1941 al invierno de 1951-52, salió a la luz una publicación destacada en el panorama de las revistas literarias en México. Rueca fue la primera revista pensada y elaborada por mujeres en nuestro país ${ }^{1}$. En entrevista con

\footnotetext{
${ }^{1}$ Hacia fines del siglo XIX había revistas que publicaban lo que los editores consideraban que debían leer las mujeres, pero en sus comités editoriales no integraban a ninguna. Esa labor no era propia del género. La
} 
María Luisa Fentanes para su investigación titulada Índices de Rueca, María Ramona Rey, la segunda al timón en esta nave, explicó el surgimiento de la revista:

Quisimos demostrar que éramos capaces de hacer buena literatura y, también, que había en México un grupo femenino que podía publicar una revista literaria seria. Esto último es quizá lo más importante. Por lo que representa de avance cultural y de promoción femenina. Sin duda, había habido en México, a lo largo del tiempo, buenas escritoras, empezando por la incomparable sor Juana, pero el concepto generalizado de que la mujer sólo excepcionalmente rebasa la mediocridad literaria, de que la literatura es en su vida un desahogo secundario, no digno de tomarse en serio, prevalecía aún en México en 1940, cuando pensamos en editar Rueca, inclusive entre los escritores. (124)

Carmen Toscano no lo quiso decir tan directamente, aunque algo de esto mencionó en su intervención en el ciclo de conferencias sobre revistas literarias organizado por el Departamento de Literatura del Instituto Nacional de Bellas Artes, en 1963. Ramona Rey sí consideraba este proyecto como una participación decidida de un grupo de mujeres universitarias, de la Facultad de Filosofía y Letras de la Universidad Nacional Autónoma de México, que se encontraban en condiciones de paridad intelectual frente a sus compañeros de generación varones, amigos, quienes ya estaban publicando otra revista, Tierra Nueva. Prosigue Ramona Rey:

¿Cómo explicaría usted lo que nos sucedió, a Pina Juárez Frausto y a mí con Tierra Nueva? [se dirige a Carmen Fentanes] Esta revista apareció en enero-febrero de 1940 y en su lista de responsables (Jorge González Durán, José Luis Martínez, Alí Chumacero, Leopoldo Zea) no figuró ningún nombre femenino, tal y como ocurría con las otras revistas literarias que por entonces se publicaban. Pero nuestra relación con Tierra Nueva había sido estrecha. Todos sus "responsables" eran excelentes amigos y compañeros universitarios míos y de Pina; ella y yo, que éramos amigas desde antes de conocerlos, habíamos asistido al proyecto y a la formación de la revista; a Pina, su novio Jorge, que

excepción fue Violetas del Anáhuac, "Periódico literario redactado por señoras" (1887-1889), dirigida por Laureana Wright de Kleinhans. Elena Urrutia asienta en "Rueca: una revista literaria femenina" que "Si bien Violetas... publicó una buena cantidad de poemas, cuentos y prosas líricas, no se puede decir que fuera una revista literaria ya que eran diversas las materias tratadas con un propósito principalmente de divulgación pero, eso sí, de ninguna manera fue un órgano frívolo o mundano" (369). Se debe apuntar la emergencia y desaparición de otras revistas 'femeninas' como La mujer mexicana (1904-1908), La mujer moderna (19171919), y Mujer (1926-1928), que definitivamente configuraban otro perfil de intereses y lecturas, muy diferentes a los abocados al serio estudio literario y producción artística considerados por Rueca. 
llegaría a ser su esposo, la animó a escribir y la hizo debutar en Tierra Nueva; de mí sabían que escribía desde niña; conocían el criterio literario de ambas por nuestros cursos comunes; a las dos nos pidieron colaboración, haciéndonos el honor de incluirnos en el primero y el segundo números... pero no quisieron hacernos un sitio literario a su lado. ¿El mérito tenía que ser absolutamente masculino? ¿O incluir entre los responsables de Tierra Nueva a chicas tan jóvenes -yo sólo tenía dieciocho años- mermaría la seriedad de quienes sólo nos aventajaban en cinco y ocho? (124)

Y continúa haciendo hincapié en su seriedad intelectual. Ambas habían sido discípulas de José Gaos en un seminario sobre filosofía medieval, en la UNAM, del cual resultó el libro Del Cristianismo y la Edad Media publicado por El Colegio de México con sendos ensayos de Pina Juárez y de Ramona Rey. Parafraseando a esta última diríamos que el filósofo español naturalizado mexicano sí había mostrado confianza en la formación intelectual de las jóvenes -un poco sus discípulas-, aunque sus compañeros no. Líneas más adelante en la misma entrevista, Rey aclarará que todo este sesgo y discrimen no era una postura personal del grupo terranovista sino una actitud generalizada, un prejuicio que venía arrastrándose desde épocas anteriores y continuaba en esa década hacia la literatura escrita por mujeres.

El primer directorio de Rueca, que se modificó algunas veces añadiendo y restando integrantes, estuvo conformado por Carmen Toscano, María Ramona Rey, Pina Juárez Frausto, Ernestina de Champourcin, María del Carmen Millán, Emma Saro y Emma Sánchez Montealvo, aunque la efusividad y participación de Sánchez Montealvo sólo alcanzó para el primer número. A partir de este primer grupo, la dirección fue mudando nombres: Emma Saro dejó de colaborar tres ediciones antes del número 20, el último de la revista, debido a que contrajo matrimonio. Pina Juárez lo mismo: se casó y cesó su relación con la revista a partir del número 16. El resto de las seis fundadoras dejó de pertenecer al directorio editorial no por motivos de matrimonio sino por las serias dificultades que les acarreaba, por nuevos compromisos adquiridos y también para abrir el paso a mujeres más jóvenes que querían tomar la estafeta. Así Martha Medrano, Helena Beristáin y Lucero Lozano tomaron la responsabilidad, pero sólo la primera de estas tres fue la única que llevó a término el No. 20 de la revista.

El elenco de dirección, pues, fue el siguiente: Carmen Toscano, María Ramona Rey, Ernestina de Champourcin, Emma Saro estuvieron del número 1 al 17; Emma Sánchez 
Montealvo solamente en el 1; Pina Juárez Frausto del 1 al 16; María del Carmen Millán del 2 al 17; Laura Elena Alemán del 6 al 16; Margarita Mendoza López en el 17; Margarita Paz Paredes también en el 17; Martha Medrano los tres últimos: del 18 al 20; Helena Beristáin y Lucero Lozano en el 18 y 19. En el grupo de fundadoras se reconoce a: Carmen Toscano, María Ramona Rey, María del Carmen Millán, Ernestina de Champourcin, Emma Saro, Pina Juárez Frausto y Laura Elena Alemán.

En los veinte números de sus once años de duración participaron 365 autores, de los cuales 84 fueron mujeres, y de estas últimas aproximadamente la mitad colaboraron con poemas. La nómina de poetisas se reparte más o menos de forma equitativa entre mexicanas y extranjeras, teniendo presencia latinoamericana, estadunidense y alguna vez europea. En todos los números se mantuvo un promedio de dos poemas escritos por mujeres, aunque es difícil afirmar que esto se haya debido a un "programa", una idea concreta de incluir ante cualquier circunstancia la presencia femenina en este género literario. Carmen Toscano reflexionaba más de una década después de finalizada Rueca que "aquello de que fuera una revista hecha por mujeres, pareció probablemente un alarde de independencia dentro del patriarcado en que vivimos, pero más bien lo hicimos para darle una característica.” (97), y añadía, porque "la importancia, la personalidad de la revista, se miden en razón de sus colaboradores, del fin que se proponen al publicarla.” (93) Y el propósito, el fin de esta revista era muy sencillo: tener una mayor participación directa en la hechura, en el diseño de una publicación, más que el desarrollo de un proyecto feminista.

El primer número contiene tres poemas de Carmen Toscano que acusan un desborde lírico como característica más sobresaliente, la manifestación de la expresión subjetiva inunda sus versos tendiendo mucho hacia el sentimentalismo en lo que definitivamente no es muestra de su mejor escritura. Más adelante se revelará como buena narradora y guionista. Estamos en la década de 1940 y México ya ha conocido las ráfagas tremebundas de los estridentistas quienes lanzaron al aire, a principios de los 20, sus aullidos volcados en tres números de su magacín Irradiador en cuya segunda entrega anunciaban: "Quitará el sueño a los reaccionarios y afirmará todas las inquietudes de la hora presente" (1923, no. 2, sp). No es que este grupo haya inquietado todas las conciencias, según advertían en su programa, pero sí significaron una voz nueva e inusitada en el espectro de las revistas literarias del país, invitaban a destruir las formas, a tomar en cuenta los modernos inventos de las urbes, a 
escuchar a esa nueva clase social que emergía en estos lares: los obreros. A finales de la década se presentó en el escenario literario la revista Contemporáneos (1928-1931). Su grupo, una "ínsula de soledades" como le llamara uno de sus poetas integrantes, Xavier Villaurrutia, ha sido uno de los más importantes de la historia literaria del país. Con su aire fresco y una actitud provocadora y crítica sacudieron el polvo de las estanterías sobre todo poéticas, subiendo los estándares de creación. Dos años de que Rueca apareciera, José Gorostiza había publicado Muerte sin fin; un enorme poema en muchos sentidos; y una versión del significativo poemario de Villaurrutia, Nostalgia de la muerte, salió de las prensas de Miguel N. Lira en 1933. En palabras del investigador estadunidense Merlin H. Forster, Contemporáneos era "un círculo reducido de amigos que entre los años 1920 y 1932 colaboraron en una serie de trabajos literarios" (7) e identifica en ellos tres subgrupos divididos por edades y afinidades. Al tiempo de Rueca se despliega, ya lo mencionábamos líneas arriba, Tierra Nueva (1940-1942), revista empujada por jóvenes de gran aliento, entre ellos dos poetas: Alí Chumacero y Jorge González Durán; a la par del crítico e historiador José Luis Martínez y del filósofo Leopoldo Zea.

A decir verdad entre los integrantes de las dos revistas hay muchas líneas entrecruzadas. Toscano conoció a José Luis Martínez en los patios de la Facultad de Filosofía y Letras de la UNAM y a partir de esa primera plática los unió una gran amistad. Comenta que “Alí Chumacero, Jorge González Durán y Leopoldo Zea, eran amigos de Pina, de María Ramona y de María del Carmen. Más tarde Jorge se casaría con Pina. Todos ellos nos critican, nos ayudan y, más que cruzar por el panorama de Rueca, visitan nuestra isla con gran confianza, como si fuera la suya” (102). María Ramona Rey agregará que nunca la creación de su revista tuvo un sesgo "feminista", pero sí, "La reticencia masculina nos obligó, indirectamente, a formar un grupo exclusivamente femenino" (127). Habría que señalar que la mitad del grupo terranovista, José Luis Martínez y Jorge González eran de Jalisco, y Alí Chumacero aun cuando había nacido en un pueblito de Nayarit, se mudó en su niñez a Guadalajara. Ahí se conocieron los tres y después continuaron su amistad en la Ciudad de México, en la Facultad de Filosofía y Letras. Otro factor de cohesión de los terranovistas fue la figura de José Gaos, mentor directo de Leopoldo Zea -el filósofo del grupo- e indirecto de los otros tres. 
Laura Elena Alemán eligió para su primera entrega en Rueca, "Canto nocturno", una melodía melancólica que no se desprende aún de tópicos de un tardío romanticismo donde el ánimo triste inunda la atmósfera. En subsecuentes números insistirá en el género lírico de tono intimista, sin embargo su fuerza se revelará en el ensayo. Ernestina de Champourcin, figura clave en la revista, escribe "Lo mío" en el No. 2, una reflexión sobre la orfandad. Cómo decir la paradoja de un hueco hondo que se cava en lo que no está, la insalvable distancia de lo que se ha visto forzado a separarse.

Mi deseo clavado en doble cruz de afanes se distiende y disloca entre rumbos contrarios. (Rueca, 1941, no. 2,24$)^{2}$

Y sin embargo todo permanece en una memoria, aún sin nosotros ya entonces ahí. El hombre debe estar consciente de que lo único que puede afirmar que posee en esta vida, le pertenece sólo para sí en una especie de distancia sin involucrar la posesión en el sentido más lato de la palabra. Lo que tenemos nunca es del todo nuestro y eso debe enseñarnos el camino de la desposesión, la libertad del desprendimiento. Champourcin lo dice, aunque en cierto momento nos haga ver la dureza de ese desprendimiento: “Cada vez más sola, cada vez más rica / [...] Cada vez más honda” (no. 2, p. 27); y confirma "¡Con un amplio gesto recorre la tierra / el que nada quiere y todo lo dio!"” (p. 27). Ernestina había llegado a México en junio de 1939, junto con su esposo el poeta Juan José Domenchina, en la oleada de emigrantes españoles expulsados de su patria a raíz del destierro de Manuel Azaña y la victoria de la dictadura. Amiga y discípula de Juan Ramón Jiménez estuvo antologada en la colección de Gerardo Diego, Poesía española, de 1934, junto a los grandes poetas de la generación del 27. En ese mismo número de Rueca, la cubana Isa Caraballo presenta "Mar de octubre", unas coplas sencillas y frescas con todo el sabor de lo popular; y "Mar sin ti" donde desarrolla en juguetonas cuartetas, lo mismo que en los versos anteriores, una preocupación nuclear en ese momento en su pensamiento y que se vuelve motivo: el mar. Es sintomático ver la coincidencia temática, aunque de signo contrario, con el poema de Mada Ontañón incluido en el número siguiente, “Canción al mar en tres tiempos” (1942, no. 3, p. 4). El nombre de Mada antes de casarse con el escritor Eduardo de Ontañón era Magdalena Martínez Carreño.

\footnotetext{
${ }^{2}$ En adelante sólo se señalará año, número de la revista y número de página.
} 
También ella hizo su vida en nuestro país a cuyas playas arribó desembarcando del Sinaia $^{3}$ en junio de 1939. En el poema mencionado se pronuncia por hablar de un "verdadero mar, un mar "hosco", con "fauces sangrándole", "un infierno frío y salado", es un mar de odios y no aquel de las canciones de sirenas. Letras de ecos terribles. Esa gran masa oceánica no simboliza ningún enlace o reunión, no es anuncio de reencuentro, sino de separación y de desgarro, primordialmente. Mada variará el tema en el ejemplar de otoño-invierno del 45-46 donde dedicará toda una tirada de versos para "Juana Inés de la Cruz".

Regresando a Champourcin, encontraremos de ella otros cinco poemas en el número de la primavera del 43. Aquí lo sentimental priva por sobre el interés estético. Un hondo dramatismo se hace presente. Por ejemplo en "Diálogo":

Regazo vacío...

- ¿Sabes algo tú del viento encendido

que tal vez lo azota?

-Senos lacios, fríos...

- ¿Acercaste a ellos tu boca llagada

en busca de alivio?

-Manos torpes, lentas...

¿QQué les has pedido?

-Corazón sin savia...

- ¿Acaso lo has visto?

estrujar su angustia al sentirse vivo? (no. 6, p. 17)

En la entrega cuatro se anotarán los nombres de Marina Romero quien colabora con "Ya no hay tiempo" (1942, pp. 18-19), imágenes muy contrastadas de técnica moderna; "Se fue quedando vacía" (pp. 19-20), un poema con fuertes ecos de romance cuyo tema es la soledad dolorosa de una mujer; y "Pescador" (p. 20), deliciosa décima con un par de versos que cumplirían la función de estribillo integrado, en ella conjuga magistralmente un toque de ironía resuelto en desilusión. Ediciones Rueca le publicó en 1943 el poemario Nostalgia del mañana. Junto a Romero aparece Zarina Lacy con una escritura tambaleante y desmerecedora. Ya había colaborado con otro poema en el número dos tampoco sin ninguna

\footnotetext{
${ }^{3}$ El Sinaia se ha vuelto altamente emblemático porque fue el primer buque que llegó a las costas veracruzanas con un cargamento bastante singular: 1,600 pasajeros exiliados de España que buscaban refugio en México bajo la anuencia del gobierno de Lázaro Cárdenas. Desde entonces se hace referencia a él como "el buque de la tristeza", insignia del exilio, aunque también puede ser visto como el buque de la salvación.
} 
gloria. De esta autora se sabe y recuerda muy poco y casi siempre su nombre sale a colación por haber sido mujer del famoso pintor mexicano Ricardo Martínez de Hoyos.

Gabriela Mistral envía desde Chile su "Hay dos...", un canto que enlaza la gran región de culturas primigenias desde el Cuzco hasta el Mayab, dos destinos con la impronta del origen de grandes pueblos indígenas, el inca y el maya. Los versos navegan entre la oda y la elegía, todo un trabajo de equilibrio y tensión entre estas antípodas, y un excelente ejemplo de su poesía generosa y telúrica.

Hay dos fuentes en la Tierra:

son el Cuzco y el Mayab.

como sus brocales arden,

se las tiene que encontrar.

Hay dos estrellas caídas

a espinales y arenal.

Nos las contaron por muertas

en cada piedra de umbral.

El canto que les ardía

nunca dejó de llamear, y a más andamos más crecen

como el padre Aldebarán. (1942, no. 5, p. 17)

La volvemos a encontrar en las páginas del No. 17 con otro poema de voz potente, cimbrante, donde paradójicamente se da cuenta con cierta ternura, de una mujer que ha cerrado su alma como se cierran los postigos o las puertas, para no ver la violencia aunque con ello también expulse la vida.

A su compatriota Stella Corvalán le leemos en el No. 6 "Fechas alrededor de mi vida" y "Responso de mi sangre". Tres años antes, en 1940, había salido su primer libro Sombra en el aire, y en el mismo año que colabora para Rueca se imprime Palabras al cual pertenecen ambos poemas. Corvalán es en nuestros tiempos referencia obligada en su geografía y en el mapa literario mundial. Desde Palabras la santiagueña se alejó de las contagiosas modas de vanguardia y eligió el limpio camino de los vocablos transparentes a los que devolvió su espesor. Se despojó sin ningún problema de sentimentalismos y sin el lastre de ese modo patético del amor habló del cuerpo modificando sin ataques y sin denuestos, con un giro sutil, el solo signo de la maternidad, de la fertilidad, cifra todavía para muchos de lo femenino. Por eso elige para el poema, como contraste, el concepto "responso", un canto dedicado a los 
difuntos. "Canto a Gabriela" vendrá después, en el No. 18, una loa con evidente dedicatoria a la Mistral.

Cómo decir, Gebriele, esa palabra que te copiara el ademán herido, la sangrante ternura de tu entraña, la dolida ansiedad de tus abismos. ¿Acaso pueden estas torpes manos abarcar la grandeza de tu sino? (1948, p. 9)

De El Salvador, Claudia Lars, seudónimo de Margarita del Carmen Brannon Vega, mandó para Rueca los poemas "Reto" y "Hermanos", en ambos expone un vasto conocimiento de las formas métricas de la tradición hispanoamericana, aunque tal vez el manejo de los temas no despliegue todavía una maestría que se mostrará viva en su posterior producción como Sobre el ángel y el hombre (1962) o en la compilación Poesía última, fechada en 1972. Sus primeros poemas denotan un esforzado batallar con la forma, de lo que resultarán muy bien trabados sonetos. Diez años antes de sus colaboraciones en la revista mexicana ya tenía Estrellas en el pozo (1934), y para 1946 sale de la prensa Romances de Norte y Sur. Experimentada en su oficio, sabrá darle respiro y reposo, porque sabe que la poesía a veces es también asunto de paciencia.

"Hermanos"

Peso del aire, vuelo de la tierra, en opuesta verdad y simbolismo.

Doble color del cielo y del abismo que el ojo exacto de la vida encierra.

Sal aceptada. Dulcedumbre en guerra.

Paisaje del espejo y de ti mismo.

Isla del sueño. Musical bautismo.

Ángel sin voz, que amarra y que destierra.

Vamos, -niños de polvo, gotas ciegas-, en ansias verticales o vencidas, cumpliendo lo mandado por entregas...

Es anillo de muerte el que nos junta, y en asombro de encuentros y partidas se vuelve de ceniza la pregunta... (1943, no. 8 , p. 20) 
Con otro vibrato y otra pulsión encontramos las entregas de la estadunidense Muriel Rukeyser, nacida en 1913, activista de derechos sociales, defensora de la igualdad y contra la persecución judía, habló en una obra temprana, El libro de la muerte (1938), impreso a sus 25 años, del deceso de cientos de mineros por silicosis en la construcción de un túnel en Virginia. Rueca incluyó en el No. 9 "El alma y el cuerpo de John Brown", poema largo aparecido por primera vez en su lengua original en 1940. Se trata de una referencia y tributo a la labor abolicionista del norteamericano decimonónico. Brown, en el poema, es símbolo de todos los esclavos negros.

Su vida está en el cuerpo de los seres que existen.

Cuando por primera vez fue ahorcado, saltó su imagen

en el aire ennegrecido. Su tumba eran los flotantes rostros

de la multitud y esquivándolos libre

alzóse, con los ojos abiertos al otoño, fanática

atalaya de fiereza saltando hacia su encuentro, desafió los blancos profetas de la tempestad

los torrenciales meteoros de la guerra.

¡Soñador Ezequiel, amenázame en vida! (1943-44, p. 10)

"Easter Eve" se compilará en el No. 15, un especial dedicado a la literatura norteamericana. Traducido en la revista como "Vísperas de Pascua", en el poema Rukeyser aún alienta una esperanza en el hombre pese al terrible holocausto producido por la Segunda Guerra Mundial, y confía en una paz, pero no aquella que se define por ausencia de las brutalidades bélicas "sino una intensa llama continua. / Para todos los hombres: esfuerzo es libertad, esfuerzo es paz, / lucha. Y por el camino de estas verdades vuelve el alma al hogar / vuela en su enardecimiento a un sitio / más seguro y completo que el Paraíso" (1945, p. 34). Son versos gestados en el mismo estilo realista, de denuncia, apegados a los acontecimientos sociales y políticos de su época. Esta es la impronta de su obra, y en esa época especialmente delicada de conflagración mundial, su voz no será un eco menor; por el contrario, es sonora y áspera, con una fuerza como de cien batallones exigiendo, más que solicitando, no más muertos sino vida, vida en libertad y justicia.

Nuria Balcells o Parés apenas si alcanza la veintena en 1944, cuando Rueca le publica “Árboles". Es, efectivamente, un poema inocentón donde no se asoma nada de su vigor posterior. Exiliada de España, desde los trece años en París tocaba la guitarra para ganarse el sustento. Con escala en La Habana, igual que tantos otros refugiados, llegó a México en 1943. 
Al casarse con el médico Carlos Parés mudó su apellido y comenzó a relacionarse de manera más profunda con el grupo de intelectuales españoles del exilio: León Felipe, Pedro Garfias, Max Aub, Enrique Díez-Canedo, José Bergamín, Luis Cernuda. De ella conocemos sus múltiples traducciones literarias del francés y del inglés, y sus poemarios posteriores Romances de la voz sola (1951), Acapulco (1959), Canto llano (1959) y la compilación de su obra Colofón de luz (1987), entre otros. No ha sido considerada una voz central entre los poetas de la posguerra española y sin embargo su tema o motivo nodal es esa herida de no tener sino el suelo prestado generosamente por otros. En Canto llano, tal vez su escritura más representativa, incluye, por ejemplo, el poema "Canto a los míos", en él anota:

Vivimos de prestado: no vivimos.

Fuimos menos que el sueño

de una generación, la fronteriza

de todos los anhelos.

$[\ldots]$

Sé que la juventud pasó de largo

o que nacimos viejos, con la sangre entibiada, cansados del esfuerzo que otros realizaron. Ellos fueron la voz y nosotros el eco, ellos fueron la llama nosotros humo denso ellos fueron la imagen de la vida nosotros el espejo... (1959, pp. 29-30)

Esta frase adjetival "generación, fronteriza de todos los anhelos" ha quedado como una marca que describe fielmente a toda una franja de personas que fueron obligadas a dejar su territorio de origen, y que desde entonces no pertenecen ni a un lado ni a otro. Están con el espíritu partido, con las raíces echadas al viento, ramas que no logran del todo un asidero, como víctimas de una antigua y fantástica maldición de un cuento infantil; pero que en la realidad no tiene nada de fantástico y menos de infantil. La vida real es así: no hay sino camino por delante, hacer otra casa en otro suelo, y buscar, siempre buscar en la memoria los sonidos, los retazos de imágenes de aquello que alguna vez pudieron nombrar con el colectivo "nuestro". 
A la dominicana Natalia Martínez Bonilla la encontramos en el No. 16 de la revista mexicana, del año 1946, con "Poema de eternidad cansada". En él domina el lirismo al expresar la pesadumbre de llevar a la vida como una carga, como un "vestido" "ajado", y además "ajeno":

Déjame hablar ahora,

antes de que el silencio eche raíces

en mi voz. Antes de que la tierra

me apriete entre sus brazos áridos y negros.

Antes de que mis párpados se cierren

sobre mi mundo vivo, con las llaves del sueño.

Déjame preguntarte por qué, si ya estoy muerta,

respiro todavía, como por una inmensa herida abierta.

Por qué mis manos tiemblan ávidas de luceros.

Por qué mis ojos siguen la ruta atormentada

de un ensueño perdido. Por qué, ¡si ya estoy muerta!

Mi vida es algo así como un vestido ajeno

que me hubieran prestado,

sin consultarme antes si me gustaba o no.

Como un vestido ajeno

que yo debo llevar aunque esté ajado,

roto, anticuado o desteñido.

Y este ajeno vestido

parece que está hecho de un material tan burdo,

que me pesa, y me estorba, y me deprime.

En veces, yo he querido restaurarlo como un traje vulgar,

zurcir sus rasgaduras, y hasta variar la moda

que ya resulta antigua

¡Pero este infeliz vestido,

no es ni siquiera mío!

Y como poco a poco envejece y se acaba, pienso que quizá un día, cuando menos lo espere, caerá el suelo, deshecho, y se hundirá en el polvo junto con mis heridas y mis llagas.

¡Barca desvencijada que se tragan los mares

mientras sobre las olas flota una vela blanca!

Mi alma, desnuda y sola, se alzará como un voto, sin la triste atadura de la carne dolida...

¡y que bella ascensión, sin esa carga

del vestido prestado que es mi vida!

Pero, ¡cuánta mentira rodando en un minuto

devorador y amargo! ¡Es mentira, mentira!

No quiero desceñirme este vestido 
con que te amo en la tierra como te amé en el cielo.

Ancla desesperada de mis sueños

clavada en las arenas

de tu radiante eternidad de estrella.

Crecida infancia triste que se arrimó a tu lumbre

para no ver el rostro de la esfinge, grave y atormentada.

Desolado remanso que se acostó a dormir sobre tu valle

y se dejó arrullar por la flauta lejana de tu voz espigada.

¡Tú, por quien he vivido

y por quien no quisiera morir,

porque acaso al morir no sepa comprenderte:

ciñe con fuerza a mi alma este vestido,

para que no lo arrastre

la ola embravecida de la muerte! (42-43)

Natalia fue integrante de la Juventud Democrática en República Dominicana con una intensa actividad contra el dictador Leónidas Trujillo, por lo que tuvo que dejarlo todo y recomenzar en Puerto Rico. Además de poemas escribió obras de teatro y novelas que tuvieron mucha difusión adaptadas para radio y televisión en Puerto Rico. Su tono dramático y la proximidad del verso con el ritmo narrativo la alejan de retóricas grandilocuentes; particularmente en el poema transcrito líneas arriba el lenguaje directo ayuda a enfatizar la fatiga de la vida que transcurre en lo que pareciera una eternidad implacable y no deseada. Tal vez sea ella una de las voces de Rueca que puedan considerarse feministas y con un alto sentido de conciencia social, de urgencia por el reconocimiento de una igualdad de género.

Y también aparece entre esta cauda de potentes voces, unas en formación, otras con estilo ya definido, la joven Rosario Castellanos, con veintitrés años. "Muro de lamentaciones" (después pertenecerá al corpus del libro De la vigilia estéril, 1950) es un poema compuesto por ocho partes; versos plenos de vigoroso clamor. No es una voz doliente en sordina, no es un murmullo de rezo ni un llanto apagado. Es un grito poderoso como el de la madre del griego Héctor, el domador de caballos, al ver a su hijo desmembrado por Aquiles. Es curioso pero las evidencias en sus versos resuenan con una diferencia; es como si nos llevaran de la mano hacia la verdad, sus palabras calan en lo más profundo, nos exigen atención ahí donde nadie quiere mirar, y nos muestran un dios hecho a la medida de lo humano:

¿Dónde estás? ¿Por qué apartas tu rostro de mi rostro?

¿Eres la puerta enorme que esconde la locura, 
el muro que devuelve lamento por lamento?

[...]

Si no existes

yo te haré a semejanza de mi anhelo,

imagen de mis ansias.

Llama petrificada

habitarás en mí como en tu reino. (1948, no. 18, pp. 23-24)

Helena Beristáin también escribe en este número 18, "Porque el aire conciso...", pero sabemos que su ruta no será la poesía sino la investigación académica. Con muchas dificultades Martha Medrano sacó a la luz el último número, con una separación entre el 19 y el 20, de casi tres años. En éste encontramos un espléndido "Nocturno", de Rosario Castellanos, en donde ha sabido combinar la melancolía de una tierra, su lugar de "íntimas huertas", "árboles encendidos de trinos", "hierba temblorosa bajo la última lluvia", un sitio que lucha por hacerse presente en su memoria, pero dejada atrás por la historia misma y por la experiencia personal de la voz que se expresa como en sordina a lo largo de una música ritmada en el lento tempo de una sonata

\section{$[\ldots]$}

Arrullemos

con canciones de cuna a la memoria

y amemos esta zona devastada.

$[\ldots]$

Todos los seres aman su destino.

Nuestro destino es padecer la noche. (1951-52, no. 20, pp. 26-27)

Cierra las colaboraciones de las poetas en esta pionera revista mexicana en su género, la alicantina Trina Sánchez Mercader con una triada: una casi elegía dedicada a su patria “Galicia”, seguida de "Detrás de mí” y "Dos poemas”. María del Carmen Millán, con motivo de un homenaje a la revista, en 1944, pronunció unas palabras de agradecimiento a la Biblioteca Benjamín Franklin de los Estados Unidos por haber asumido el coste del premio anual, fomentado por la propia Rueca, otorgado a un escritor cuya obra se hubiera distinguido. En esa ocasión lo mereció Alí Chumacero por su poemario Páramo de sueños. En su alocución, Millán argumentaba que Rueca

No trata, con todo, solamente de dar gusto a los iniciados poniendo a su alcance los tesoros culturales, sino que por todos los medios posibles: radio, prensa, conferencias, exposiciones de 
arte, etc., se empeña en ampliar una atmósfera cultural a la que se acostumbre el mayor número de personas para quienes sea después vital este nuevo ambiente espiritualmente más alto y rico. Su tarea es educativa; es el deseo bien entendido y bien realizado a la vez, de unificar la heterogeneidad característica de nuestro pueblo. $(1945$, no. 15, p. 74$)$

Guiños tiene la vida. Uno de los compañeros terranovistas fue galardonado por sus pares aun cuando no se reconocerán intelectualmente como tales. Y unas palabras muy justas para la labor que desarrolló esta revista que llegó a ser catalogada como una de las más interesantes en su época, que no sólo dio a conocer la obra de varias poetas jóvenes y difundió la obra de aquellas con mayor solidez en el oficio, sino que se destacó por una equilibrada visión en el panorama de la literatura.

\section{Bibliografía}

Bados Ciria, Concepción. "Republicanas exiliadas en México". Revista literaria Rinconete. http://cvc.cervantes.es/el_rinconete/anteriores/marzo_07, 2007.

Fentanes Rodríguez, Luz de Carmen. Índices de Rueca, tesis de licenciatura, México: UNAM, 1982.

Forster, Merlin H. Los Contemporáneos 1920-32. Perfil de un experimento vanguardista mexicano. México: Ediciones de Andrea, 1964.

Irradiador, 2. México: Librería de César Cicerón., octubre de 1923.

Martínez, José Luis. Literatura mexicana siglo XX. 1910-1949, México: Conaculta, 1990.

Parés, Nuria. Canto llano. México: FCE, 1959.

Rey, María Ramona. Entrevista en Índices de Rueca. Tesis de licenciatura de Luz de Carmen Fentanes Rodríguez, México: UNAM, 1982.

Rueca. Revistas literarias mexicanas modernas, 20. (1941-invierno de 1951/1952), México: FCE, 1984.

Toscano, Carmen. "Rueca”. Las revistas literarias de México. México: INBA, 1963. 93-112.

Urrutia, Elena. "Rueca: una revista literaria femenina". Nueve escritoras mexicanas nacidas en la primera mitad del siglo XX, y una revista. México: Instituto Nacional de Mujeres, El Colegio de México, 2006. 367-384.

Urrutia, Elena. "Carmen Toscano" en Nueve escritoras mexicanas nacidas en la primera mitad del siglo XX, y una revista. México: Instituto Nacional de Mujeres / El Colegio de México, 2006. 385-390. 